\title{
Association for Library Collections and Technical Services Annual Report 2014-15
}

\author{
Mary Page, 2014-15 ALCTS President
}

$\mathrm{T}$

he Association for Library Collections and Technical Services, a division of the American Library Association, is the premier organization for professionals in collection development, cataloging and metadata, continuing resources, and preservation. Comprising nearly 3,000 members from the United States and more than forty countries, we lead the development of principles, standards, and best practices for creating, collecting, organizing, delivering, and preserving information resources in all formats.

\section{Accomplishments}

Perhaps the most significant event this year was the retirement of Charles Wilt, our beloved executive director, after a seventeen-year career at ALA. It was a bittersweet moment for ALCTS. However, we were very fortunate to hire Keri Cascio as our new executive director. Keri brings a wealth of experience in many different library settings—research, public, consortial—and she has long been active in the association. In fact, she was ALCTS' first Emerging Leader back in 2007, which gives her career thus far a lovely symmetry.

Led by the Planning Committee under chair Meg Mering, we developed a new strategic plan for ALCTS, which was informed by ALA's Strategic Directions. The three-year plan was approved in principle at the 2015 ALA Annual Conference in San Francisco. The new plan takes a high-level perspective and does not delve into the operational aspects of our work. Rather, it asks that all activities focus on a few overarching goals: generate awareness of ALCTS and participation in ALCTS activities, improve member recruitment and retention, and achieve financial stability. Committees and Sections will be expected to address how their work addresses these issues in their reports.

The Program Review Task Force, led by Betsy Simpson, was charged to examine ALCTS programming and make recommendations for strategic directions, structural and procedural improvements, and new approaches to meet member needs. The task force submitted its final report to the ALCTS board, and we approved most of its recommendations at the ALA Annual Conference. A key recommendation is to establish a Program Coordinating Group, which will be composed of the leaders (or designees) of the many groups involved in ALCTS 
programming (e.g., Continuing Education and Program Committees, the interest group coordinator, etc.).

The Fundamentals of Cataloging web course was brought to fruition under the leadership of Vicki Sipe, and it is already a great success. Five sessions of the six-week online course have been scheduled in 2015, and four of those have sold out.

ALCTS 101, held each year at the ALA Annual Conference, is designed to inform new and potential ALCTS members about possible ways to become involved. This past spring, we held a virtual ALCTS 101 program that attracted more than 230 registrants. At the ALA Annual Conference, the in-person ALCTS 101 session drew more than 70 participants, and we inaugurated the first-ever ALCTS 101 After-Party. The Membership Committee and the ALCTS New Member Interest Group (ANMIG) reinvigorated communication with new and renewing members and spearheaded the launch of ALCTSCentral, a general electronic discussion list for all members.

\section{Midwinter Symposium}

ALCTS' Midwinter Symposium, Collection Development Strategies in an Evolving Marketplace, featured Lorcan Dempsey and Constance Malpas of OCLC Research. The well-received symposium attracted more than fifty-five attendees. Warm thanks to the President's Program Planning Committee led by chair Marilyn Geller for conceiving the program. Thanks as well to Michael Levine-Clark, who organized and hosted the daylong session and made this stellar event happen.

\section{Fundraising}

Under the leadership of Lenore England, the Fundraising Committee has worked hard to develop a culture of philanthropy within ALCTS, and it surpassed its goal of raising $\$ 20,000$ for the year.

\section{Publishing}

We appointed a new ALCTS monographs editor, Susan E. Thomas, to begin her term in June 2015. Susan brings years of experience in writing and project management to this newly revised position, and we are eager to reinvigorate our publishing program. ALCTS Publishing released the Guide to Ethics in Acquisitions by Wyoma vanDuinkerken, Wendi Arant Kaspar, and Jeanne Harrell in early 2015. The Critical Component: Standards in the Information Exchange Environment, edited by Todd A. Carpenter, was published in June 2015. Library Resources \& Technical Services, ALCTS' peer reviewed research journal, went online-only with the January 2015 issue. The AcqNet electronic discussion list is in the process of transferring to the Acquisitions Section in consideration of discussion list sustainability. CollDev, managed by an individual who retired this year, is in the process of being transferred to the Collection Management Section.

\section{Resolutions}

The ALCTS board passed resolutions to honor the memory of some of our most dedicated members. Julia Blixrud, Ruth C. Carter, Lois Mai Chan, Cynthia D. Clark, Judith Hopkins, and Mary Woodley were among the best of us. They are sadly missed.

\section{In Closing ...}

I want to acknowledge ALCTS' wonderful Executive Committee: Past-President Genevieve Owens, President-Elect Norm Medeiros, and Councilor Andy Hart- dear friends and colleagues all. While I struggled through the formalities of parliamentary procedure or attempted to lead a difficult board discussion, they provided support, counsel, and good cheer. I was fortunate to have retired Executive Director Charles Wilt by my side during the first half of my presidency, and equally fortunate to have Keri Cascio with me for the home stretch. Both ALCTS executive directors have been a joy to work with, and I have learned so much about leadership by observing them. The ALCTS office staff, Christine McConnell and Julie Reese, were unfailingly helpful and reassuring while I learned the ropes. ALCTS is lucky to have them. The entire ALCTS board worked hard this year, and to a person, they contributed substantively to the work of the association. I am honored to know you and to have worked with you. I will end with a shout-out to the amazing ALCTS volunteers, who stand for office, donate their time and energy to sections and committees, and take on tasks large and small for the good of ALCTS and the profession. Thank you all. 